\title{
BERKELEY: LA CONCEPCIÓN DE DIOS EN LOS COMENTARIOS FILOSÓFICOS
}

\section{BERKELEY: THE CONCEPTION OF GOD IN THE PHILOSOPHICAL COMMENTARIES}

\author{
AlBerTo Luis LÓPEZ* \\ FES Acatlán - UNAM
}

Resumen: Berkeley fue un filósofo que escribió sobre temas tan variados como la filosofía natural y política, las matemáticas, la economía o la teología. Dentro de esta gama tan diversa de intereses sobresale su preocupación por el espíritu infinito, por ello el objetivo de este artículo es rastrear los orígenes de la concepción berkeleyana de Dios, cuestión que ya se prefigura en los Comentarios Filosóficos. La importancia de conocer y analizar las notas que conforman los Comentarios radica en que permiten comprender no sólo cómo se configuró la incipiente filosofía inmaterialista, sino, sobre todo -y propósito de este artículo- qué características y qué función fue adquiriendo Dios dentro de la misma.

Palabras clave: Comentarios Filosóficos, Dios, Espíritu infinito, Voluntad, Essepercipi, Inmaterialismo.

\footnotetext{
* Profesor en la Facultad de Estudios Superiores Acatlán (Universidad Nacional Autónoma de México). Av. Alcanfores s/n, Santa Cruz Acatlán, Naucalpan, Edo. de México, c.p. 53150; email: albertograco@yahoo.com.mx
} 
AвSTRACT: Berkeley was a philosopher who wrote about such diverse topics as natural philosophy, political philosophy, mathematics, economy, and theology. Within this broad range of interests, his concern about the infinite spirit stands out; thus, the aim of this paper is to trace the origins of Berkeley's conception of God, an issue which is already prefigured in the Philosophical Commentaries. The importance of knowing and analyze the notes that make up the Commentaries lies in that they make it possible to understand not only how the incipient immaterialist philosophy was established, but above all -being purpose of this paper- what features and role God acquired within it.

Keywords: Philosophical Commentaries, God, Infinite Spirit, Will, Esse-percipi, Immaterialism.

\section{Introducción}

En este artículo me propongo rastrear la concepción de Dios en la filosofía de George Berkeley, pero, a diferencia de lo que hasta ahora se ha hecho en artículos especializados, no desde la obra publicada (Principios, Diálogos, etc.) sino desde la no publicada, esto es, a partir de los Comentarios Filosóficos ${ }^{1}$. Los motivos que me llevan a ello son básicamente dos: 1) los Comentarios han sido muy poco estudiados, lo que se debe en gran medida a que se ha creído que son un simple borrador de notas inconexas, y 2) contienen en ciernes el origen de prácticamente toda la filosofía berkeleyana (lo que hace aún más inexplicable su poco estudio). Considero que si se quiere tener una mejor comprensión del pensamiento filosófico del irlandés, es imprescindible conocer y analizar las notas que conforman los $P C$, sobre todo porque se advierte en ellas el proceso que siguió para conformar su concepción definitiva de Dios, asunto fundamental para su filosofía inmaterialista.

Debido a que prácticamente no existen estudios especializados sobre los Comentarios, menos aún en lengua española -algo fácilmente constatable si uno revisa la bibliografía sobre Berkeley-, he decidido hacer una introducción a los mismos. Si bien podrá parecer un poco extensa intenta ser más bien exhaustiva,

1 Salvo que indique lo contrario todas las referencias a las obras de Berkeley son de la edición de Luce y Jessop. Me referiré a los Comentarios Filosóficos como Comentarios o como PC (siglas de Philosophical Commentaries), y al Tratado sobre los principios del conocimiento humano como Principios o como PHK (siglas de Principles of Human Knowledge). Cuando cite la introducción de Luce a los $P C$ o me refiera a otro texto de las obras completas añadiré el volumen en números romanos. 
en el sentido de que busca desentrańar para el lector el contexto que rodeó a estas notas y, de paso, dejar claro su importancia y por qué es necesario revalorizarlas. Después de la introducción haré un análisis, que hasta donde tengo noticia aún no ha sido realizado, que consiste en revisar las notas dedicadas al tema de Dios, es decir, las referidas ex professo al asunto, así como en rastrear aquellas cuya clasificación no indica relación alguna con Dios, pero que, sin embargo, tratan sobre Él. La finalidad de dicho análisis es -como anuncié- dar a conocer al lector los orígenes de la concepción berkeleyana de Dios, lo que sin duda ayudará a comprender mejor la compleja propuesta filosófica del irlandés.

\section{La obra no publicada: origen y aparición de los Comentarios Filosóficos}

El mismo año (1707) en que el joven alemán George F. Händel, nacido al igual que Berkeley en 1685, tomó la decisión de viajar a Italia para buscar prestigio como compositor, otro joven con el mismo nombre, pero de origen irlandés, decidió comenzar a redactar (en la época estival) una serie de notas sobre temas filosóficos. Éstas fueron terminadas al iniciar el otoño de $1708^{2}$, y su importancia radica en que constituyeron el esbozo de su futura propuesta inmaterialista, según comenta Arthur A. Luce en su 'Editor's Introduction' a los $P C$.

Un siglo después, en el siglo XIX, los cuadernos que contenían esas notas fueron encontrados por el filósofo escocés Alexander C. Fraser. Éste los llamó Commonplace Book of Occasional Metaphysical Thoughts y los incorporó en sus ediciones de las obras completas de Berkeley (de 1871 y 1901 respectivamente), llamadas Collected Edition of the Works of Bishop Berkeley with Annotations, etc. Fraser publicó los cuadernos siguiendo lo que consideró el orden evidente A-B, sin embargo, luego de su publicación, y de ser estudiados profusamente por otros comentaristas, surgió la controversia por el orden en que las notas habían sido publicadas. En 1905 Theodor Lorenz $(1905,551-556)$ fue el primero en proponer, para hacer las notas más inteligibles, reordenar los cuadernos en sentido B-A, y poner la última parte del $\mathrm{B}$ al final del todo (después de A); esa propuesta la llevó a cabo G. A. Johnston en su edición de 1930 del Commonplace Book (1930, IX-XXIV), quien además decidió numerar cada una de las anotaciones. Tiempo después, en 1936, John Wild propuso en su libro sobre Berkeley que se editase

2 Furlong específica que los cuadernos probablemente fueron terminados en agosto o septiembre de 1708 (Furlong, 1961-63, 1). 
dicho libro con el orden B-A, pero - a diferencia de Johnston- todo seguido, es decir, sin cambiar el orden (como originalmente propuso Lorenz). La propuesta de Wild tuvo eco en Luce, quien preparó en 1944 una editio diplomatica sobre el texto; en ésta también invirtió el orden de los cuadernos, de A-B a B-A, y los renombró como Philosophical Commentaries (posteriormente los volvió a publicar en 1948 en las obras completas de Berkeley, que editó con Thomas E. Jessop) ${ }^{3}$.

Los $P C$ son -como dije- un conjunto de notas que Berkeley escribió para sí mismo, no para ser publicadas, y por eso no cuidó tanto como acostumbraba su lenguaje, redacción y estilo. Esto es precisamente lo que hace que el texto resulte fragmentario y un tanto desconcertante; eso no significa -como sugiere Brykmann y Beyssade en su introducción a los Comentarios en las obras completas de Berkeley en francés- que se trate de una "colección de pensamientos ocasionales» o casi accidentales, sino más bien -como luego reconocen ellos mismos- que los $P C$ «constituyen una obra de investigación donde los signos marginales manifiestan un proyecto de sistematización» (Berkeley, 1985, 21). Para llevar a cabo ese "proyecto de sistematización» los editores franceses afirman que Berkeley siguió el método propuesto por Locke en un artículo de 1686, publicado en francés por la Bibliothèque Universelle de Leclerc bajo el título Méthode nouvelle de dresser des recueils. En su artículo Locke propuso un método para seleccionar y organizar los propios pensamientos, que consistía en establecer un índice que utilizaría la letra inicial del tema principal sobre el que tratase cada conjunto de pensamientos. Este método lockeano -se afirma- fue seguramente conocido por Berkeley a través de la publicación de las obras póstumas de Locke, en 1706, que incluyeron el artículo mencionado bajo el título Method for a Commonplace Book (Berkeley, 1985, 21-22).

En cuanto a la forma actual de los $P C$, teniendo en cuenta que leí y revisé detenida y pausadamente la edición anglosajona de Luce (1948), la francesa de Brykman (1985) y la mexicana de Robles (1989), me parece que es necesario llevar a cabo una revisión de las notas y, sobre todo, de los signos marginales que indican el tema de las mismas. En algunas ocasiones los signos anotados al lado izquierdo de los comentarios, que refieren al contenido temático de los mismos, no corresponden del todo con el tema sobre el que versan las notas. La propia lectura de los cuadernos pone de manifiesto que, en ocasiones, éstos fueron escritos por Berkeley impetuosamente, con vehemencia; si a esto se le añade que no tuvo intención alguna en publicar dichas notas, entonces se puede comprender

3 Para consultar estos y otros datos remito al artículo de Belfrage (1985, 196-214). 
por qué el índice de las mismas, anotado del lado izquierdo, no se corresponde siempre con su contenido. Pese a posibles divergencias sobre el contenido de las notas, considero que una importante contribución a los Comentarios sería la de realizar una edición que se sirva del índice original de Berkeley, pero haciendo algunas correcciones al mismo para que indique con mayor precisión el contenido de cada nota.

Cabe mencionar, por último, que pese a ser un escrito de juventud (Berkeley tenía veintidós años al escribir los cuadernos) que cuenta con deficiencias gramaticales y estilísticas, los $P C$ no deben ser leídos de forma rápida y superficial; todo lo contrario, tienen que leerse con atención y sumo cuidado, es decir, hay que meditarlos, porque son el origen y antecedente inmediato del pensamiento definitivo del irlandés.

\section{Contenido general y orden temático de los Comentarios}

Como se ha mencionado, los cuadernos son importantes porque contienen prácticamente todos los temas que Berkeley desarrolló a lo largo de su vida, entre ellos lo que denominó en aquel momento «hipótesis inmaterial» (PC 19). Es por ello que el período de 1707-1708 constituye «el annus mirabilis de su desarrollo intelectual», pues en esta época -como señala Luce-:

aprendió a rechazar el pan-fisicismo y a aceptar el dualismo del sentido y el espíritu; aprendió a hacer de la mente algo activo y de las cosas sensibles (ideas) algo pasivo, así como colocó las bases de su doctrina de la causa; aprendió a rechazar las ideas abstractas ${ }^{4}$ y el lugar de lo perceptible sin ayuda de la materia; sobre todo, descubrió "la obvia aunque sorprendente verdad" (No. 279), su "Nuevo Principio", el esse est percipi, el significado de la existencia sensible (Berkeley, 1948-57, I, 5).

La cita anterior muestra los muchos cambios que tuvo el pensamiento del irlandés durante los años en que escribió sus cuadernos; esos cambios se reflejan en los diversos temas anotados, los cuales hacen de sus $P C-$ a decir nuevamente

4 Robles demuestra que Berkeley, tanto en sus PC como en su IM (Introducción Manuscrita), esto es, en su obra no publicada, rechazó los términos 'idea general' e 'idea abstracta', pero aún no distinguió con claridad uno de otro, algo que sí hizo en los PHK (Robles, 1990, 85 ss). Para ahondar en el tema de la generalidad remito al capítulo 4º "Abstracción y generalidad", del mismo libro de Robles (1990, 77-99). 
de Luce- «un laberinto en el que el principiante que no cuente con pista alguna está perdido» (Berkeley, 1948-57, I, 5). Entre los muchos temas que aparecen destacan la construcción de su principio esse-percipi, el tiempo y la eternidad, el espacio y el movimiento, las ideas y el espíritu, Dios y la materia, y diversos temas matemáticos como lo cóncavo y lo convexo, los polígonos y los círculos, las líneas y puntos, las curvas y los números irracionales, los arcos y abscisas, etc.

Hablando sobre el orden de los temas, que tiene que ver con la disposición B-A establecida por Luce en su editio diplomatica, es interesante señalar que el cuaderno 'A' contiene un mayor número de notas referentes a temas propiamente filosóficos, como la materia, la moral, el espíritu, Dios, la naturaleza, la existencia $\mathrm{y}$, por supuesto, el nuevo principio esse-percipi. En cuanto al cuaderno 'B', éste está destinado a temas mayoritariamente matemáticos, aunque no por ello dejan de aparecer cuestiones filosóficas como las antes mencionadas; destacan sobre todo una serie de notas que aparecen al final del cuaderno, debido a que en ellas Berkeley estableció los preceptos de su nuevo principio $(P C 377-380)^{5}$. Es muy probable que estas notas fuesen el motivo por el cual Lorenz, y luego Johnston, creyeron necesario poner la última parte del cuaderno $\mathrm{B}$ al final de todo el texto (después del A).

El orden actual de los cuadernos, B-A, que parece ya definitivo, denota algo interesante, a saber, el interés juvenil de Berkeley por las matemáticas y la influencia que éstas ejercieron en él a lo largo de toda su vida. No parece casual, entonces, que si las primeras obras publicadas por el irlandés fueron sobre cuestiones matemáticas ${ }^{6}$, Arithmetica y Miscellanea Mathematica (1707), Luce haya decidido poner en primer lugar el cuaderno B (aunque el orden del alfabeto indicase que debía ser el A, como lo pensó Fraser). La formación matemática de Berkeley fue importante no sólo porque toda su filosofía estuvo salpicada de preceptos y reflexiones matemáticas, sino también porque gracias a ella se explica, en parte, su crítica a las ideas abstractas de Locke, ya contenida en los $P C$. Sobre esta misma cuestión, el filósofo irlandés, a diferencia de otros empiristas como Locke, Hume o Reid, al contar con una sólida educación matemática tuvo un acercamiento distinto a problemas geométricos y/o aritméticos, mezclados con perceptuales,

5 Conviene revisar lo que señala Luce sobre estas notas (Berkeley, 1948-57, I, 123).

6 En Berkeley existe lo que llamo un corpus matemático berkeleyano, conformado principalmente por los Philosophical Commentaries, Of Infinites, Arithmetica absque algebra aut Euclide demonstrata y Miscellanea mathematica, The Analyst y A Defense of Free-Thinking in Mathematics. 
tales como la longitud sin ancho de una línea ${ }^{7}$ o el problema de los infinitesimales. Su formación matemática lo llevó también a enfrentar los problemas de la abstracción y la percepción desde una perspectiva empíricamente distinta, que lo alejó de su antecesor inglés y de sus predecesores escoceses.

Volviendo al cuaderno A, que contiene la mayoría de los temas propiamente filosóficos, me parece atinado que se encuentre detrás del $\mathrm{B}$ o siguiendo a éste. En mi opinión esto es correcto, porque revela cómo ciertas posturas de Berkeley derivadas de su defensa de la teología cristiana (como su rechazo del ateísmo, el escepticismo, la irreligión o el corpuscularismo), influían decisivamente en su pensamiento filosófico. Además, el orden B-A de los cuadernos muestra también, y acertadamente, el cambio en los intereses del irlandés; por un lado se puede ver que sus intereses de juventud fueron de tipo científico-matemático, pues versaban sobre física, óptica y dióptrica, y le sirvieron para publicar su Essay towards A New Theory of Vision (1709). Estos intereses cedieron terreno, conforme Berkeley fue alcanzando una mayor madurez intelectual, frente a otros de corte más filosóficoepistémico, hasta que éstos desembocaron, a su vez, en intereses y actitudes cada vez más apologéticas de Dios y de la religión cristiana.

Por lo tanto, puede decirse que el orden B-A de los cuadernos, mejor que el A-B, pone de manifiesto - aunque sea como esbozo- la ruta que siguió el pensamiento del irlandés a lo largo de toda su vida, en la cual el tema de Dios fue ganando terreno con el paso de las notas, así como con el transcurso de los años, hasta convertirse en un asunto prioritario para su filosofía.

7 «X. Mem: una gran diferencia entre considerar la longitud sin ancho y tener una idea de la longitud o imaginarla sin ancho» (PC 254). «X. Considerar la longitud sin ancho es considerar cualquier longitud sea del Ancho que sea» (PC 722). 


\section{La presencia de Dios en los Comentarios ${ }^{8}$}

Si uno tiene en cuenta los nueve signos marginales que clasifican el contenido temático de las notas, al inicio del cuaderno A, y comienza a leer cada nota siguiendo dicha clasificación (tomando en cuenta el signo añadido por Luce [' $†$ '] que indica «lectura dudosa»), entonces la figura de Dios parece ser simplemente complementaria, apenas un accesorio. Lo anterior porque la letra ' $G$ ', de God, tan sólo antecede a cinco notas en el cuaderno B y a quince en el cuaderno A, es decir, aparece en los Comentarios sólo en veinte ocasiones; sin embargo, luego de una revisión más detallada y una lectura cuidadosa queda claro que de las ochocientas ochenta y ocho entradas que comprenden los $P C$, las ocasiones en que aparece el tema de Dios superan las cinco del cuaderno $\mathrm{B}$ y las quince del cuaderno $A$, siendo en realidad dieciocho en el primero y treinta y cuatro en el segundo (contando las señaladas con la letra 'G')'.

Con lo anterior no pretendo señalar que la figura de Dios haya sido un tema prioritario para el joven Berkeley, pues resulta evidente que no lo fue, empero,

8 En algunas notas se lee que el tratado que Berkeley pensaba escribir constaría de al menos tres partes, lo que significa que los $\mathrm{PHK}$ son sólo un fragmento de todo el texto, por eso en la primera edición se indicó que se trataba de la parte I. La pérdida en Italia de, al menos, la segunda parte de la obra influyó especialmente en el tema de Dios, pues ésta versaría sobre «Los 2 grandes Principios de Moralidad. el Ser de un Dios y la Libertad del Hombre: éstos manejarlos al inicio del Libro Segundo» (PC 508). Lo anterior permite colegir que los temas señalados con la letra 'G' (Dios), 'S' (espíritu), y 'Mo' (moralidad), junto con el tema de la voluntad, serían abordados en el segundo libro, lo que significa que sería -para los interesados en esos temas- el más importante de los PHK. El que Berkeley abordara el tema de Dios en los Diálogos, sobre todo en el segundo y en el tercero, subsanó hasta cierto punto el hueco que dejó la pérdida de la segunda parte de los Principios.

9 Al tratarse de notas en cuadernos siempre es posible interpretarlas de manera distinta a la mía, lo que incrementaría o reduciría, mínimamente, las cifras dadas.

Mencioné que las letras y signos que clasifican temáticamente las notas requieren ser revisados íntegramente, como reconoció Luce en 1970, pues como no siempre corresponden con los contenidos enunciados en ellas hay que complementar varios de esos signos. Como ejemplo señalo la ingente cantidad de notas a las que Berkeley puso el signo ' + ', y que Luce interpretó como entradas cuyo contenido fue rechazado posteriormente por considerarlo incorrecto; empero, luego de leerlas con cuidado y de revisar algunos estudios de Belfrage (vid. bibliografía), me parece que varios de los pensamientos contenidos en los $P C$, y señalados con '+', sí fueron incorporados por Berkeley en obras posteriores. Eso significa, respecto al tema de Dios, que varias de las notas señaladas originalmente con ' + ' tendrían que tener en su margen izquierdo, junto al signo escrito por Berkeley, la letra ' $G$ ', lo que implicaría añadir a los signos o letras usados por el irlandés algunos otros, con el propósito de darle mayor especificidad temática a cada nota. 
sí vale la pena destacar que la preocupación por este tema, así como por temas teológicos ${ }^{10}$, ya estaba presente en él desde sus años de juventud. Por otro lado, también queda claro que para el joven filósofo había otros temas mucho más atractivos en estos años, o al menos más acuciantes de tratar que el de Dios, pues en aquel momento este tema no era para él tan relevante como para dedicarle páginas enteras, mucho menos libros completos, como sí sucedió años después.

\subsection{La conformación del nuevo principio y su conexión con Dios}

A lo largo de los Comentarios se puede observar el proceso reflexivo que dio lugar al nuevo principio berkeleyano esse-percipi. Incluso, a modo de digresión, si uno quisiera rastrear sus orígenes podría atenerse a lo dicho por Wild, quien sugiere que este principio pudo haberse originado por la lectura del Ensayo de Locke, específicamente del capítulo sobre la «Idea de duración», así como por las meditaciones del irlandés sobre la "naturaleza del tiempo", al percatarse de que éste difería de individuo a individuo e incluso se daba de diferentes modos en la misma persona (Wild, 1962, 24) ${ }^{11}$.

No me detendré en analizar lo sugerido por Wild, porque lo que interesa ahora no es el principio berkeleyano como tal sino la conexión que guarda con Dios. Para conocerla hay que recurrir a las notas de los cuadernos, pues a partir de ellas es posible rastrear y reconstruir -al menos en parte- el proceso que siguió Berkeley en la configuración de su principio. $\mathrm{Al}$ respecto puede verse que inicialmente, en $P C 19$, se habla apenas de "M En tu hipótesis inmaterial...», lo que significa que su principio era entonces una mera conjetura, un simple proyecto; sin embargo, en $P C 194$ se da un cambio importante porque ya se no piensa en una 'hipótesis' sino en una doctrina: «+ Debido a mi doctrina...». El cambio de hipótesis a doctrina, que implica la consolidación de un conocimiento, trajo

10 En los $P C$ hay alrededor de quince entradas referidas a temas o cuestiones religiosas, siete en B $(14,17,281,293,310,339,350,350 \mathrm{a})$ y ocho en A $(405,436,584,642,715$, $720,723,786)$, que se refieren sobre todo a la Escritura y a ciertos dogmas de fe, como la transubstanciación; sin embargo, no hay signo o letra alguna, ni escrita por Berkeley ni ańadida por otro comentarista, que señale este tema al inicio de cada nota. En la mayoría de los casos a las entradas referidas a la religión les antecede la letra 'M' (de materia) o el signo '+' (vid. nota anterior). Lo anterior refuerza mi opinión sobre la necesidad de completar y adecuar el índice original de letras y/o signos escritos por Berkeley.

11 Wild se refiere al capítulo 14 ("De la duración y de sus modos simples") y 15 ("De la duración y de la expansión consideradas juntas"), del Libro II del Ensayo. En cuanto al tiempo véanse las entradas $4,5,8,9,10,13,39,48$ y 92. 
consigo que Berkeley, en la nota 279 , se sorprendiera por no haber comprendido antes lo que ahora le resultaba evidente, a saber, su propio principio filosófico: «M No me sorprende mi sagacidad al descubrir la verdad obvia aunque asombrosa, más bien me sorprende mi estúpido descuido por no haberla descubierto antes...». La nota siguiente, 280, confirma que el principio ya estaba bien definido en la mente del filósofo de Kilkenny:

Nuestras ideas simples son otros tantos pensamientos o percepciones simples, y que una percepción no puede existir sin una cosa que la perciba o por más tiempo de lo que se percibe, que un pensamiento no puede estar en una cosa no pensante, que un pensamiento simple uniforme no puede asemejarse a nada sino a otro pensamiento simple uniforme. Los pensamientos o ideas complejas son sólo una colección de ideas simples y no pueden ser la imagen de nada o asemejarse a nada que no sea otra colección de ideas simples. etc.

Pese a tener claridad sobre su doctrina, la nota 285 denota que Berkeley conocía bien las dificultades de postular su principio, pues sabía que muchos de los prejuicios arraigados en la mente de las personas jugarían en contra suya. Por eso más que apelar a los doctos, cuyo conocimiento también contiene prejuicios aunque diferentes a los de los incultos, pensó en el común de la gente. «+. Algún tipo de ignorancia es un requisito en la Persona que haya de Descubrir el Principio». La consolidación del principio aparece en las notas 377 a 378a, donde el irlandés hace una especie de resumen amplio de su filosofía e incorpora allí nociones tales como ideas, cosas, sensaciones o mente; sin embargo, sabiendo que su inmaterialismo podía no ser bien recibido, e influido por la necesidad de demostración en matemáticas (que quiso llevar a ámbitos como la ética, la metafísica o la teología ${ }^{12}$, Berkeley tuvo la intención de demostrar su principio: «+. Newton no funda su Principio, $\dagger$ yo Demuestro el mío» (PC 407), algo que -como se sabe- también intentó hacer en obras posteriores.

Luego de leer todas las notas de los Comentarios queda claro -como acabo de mencionar- que el principio inmaterial ya estaba prefigurado en la mente del autor, pese a su corta edad; también queda claro que estaba convencido de los perjuicios y beneficios que para el conocimiento humano traería el rechazo o la aceptación de su filosofía. En cuanto a los primeros, es decir, los perjuicios, afirma contundente que «M. El Reverso del Principio introdujo el Escepticismo»

12 Vid. PC 162, 163, 239, 584, 732 y 750. 
(PC 304). Esta nota se complementa con la 411, en donde queda más claro que el reverso de su principio, esto es, el «esse est non percipi» (Szałek, 2009, 153) o la aceptación de la materia, no sólo trae consigo el escepticismo sino también la «idolatría» y la «inmoralidad»; en consecuencia, la inversión del principio inmaterial era inadmisible porque resultaba perjudicial para el conocimiento humano (como él mismo señaló en varias ocasiones en sus PHK). Por otro lado, Berkeley se muestra convencido de los beneficios de aceptar su filosofía cuando señala que con ésta «M Los Filósofos pierden su Materia, Los Matemáticos pierden sus sensaciones insensibles, el Profano su Deidad extensa Ruego que me digan qué pierde el Resto de la Humanidad, respecto a cuerpos etc todavía los tenemos.» (PC 391).

Como se colige de la nota anterior, el principio inmaterialista rechaza la materia pero no los cuerpos ni la existencia de un mundo externo ${ }^{13}$. Por eso Berkeley afirma en la nota 98 lo siguiente: «M Los Árboles están en el Parque, esto es, sea que lo quiera o no sea que imagine algo acerca de ellos o no, permítaseme ir allí y abrir mis Ojos en el día y no podré evitar verlos». Lo anterior anticipa su convicción de que «M N.B. Conforme a mis Principios hay una realidad [reality], hay cosas, hay una rerum Natura» (PC 305). La conexión del nuevo principio con Dios se da a partir de que éste confirma la existencia del mundo externo, pues al hacerlo hubo que asumir que hay una realidad cuya existencia es inobjetable, de ahí que el irlandés sostuviera que con su nueva doctrina «las cosas son tan reales y existen en rerum natura tanto como siempre» (PC 535).

Al afirmar la existencia de una realidad externa inobjetable, conformada por cosas reales, es decir, que no dependen del perceptor sino que se le imponen, Berkeley se vio en la necesidad de reflexionar sobre qué era aquello que hacía posible tal imposición. Sus reflexiones lo llevaron a pensar que «G Lo que nos afecta debe ser una cosa pensante pues lo que no piensa no puede subsistir» (PC 109). ¿Qué era aquello pensante que sostenía, mantenía y/o conservaba esa realidad imponente? Sus disquisiciones lo llevaron precisamente a Dios, o a esa mente o espíritu infinito, algo que se puede ver palmariamente en la nota 433, donde se mostró convencido de que «La causa de todas las cosas naturales es sólo

13 Un error recurrente es pensar que para Berkeley no existe el mundo externo o que su filosofía lleva a la negación de éste, al no superar el solipsismo. Para responder a esta crítica basta con leer atentamente los $P C$, el $\$ 34$ de los $P H K$ o los Diálogos. 
Dios. Por lo tanto banal inquirir por Causas segundas. Esta Doctrina da una idea sumamente adecuada de la Divinidad».

\subsection{Los comentarios sobre Dios (señalados con ' $G$ ') $)^{14}$}

Es importante mencionar ahora algunas de las notas que fueron destinadas ex professo al tema de Dios, según la propia clasificación hecha por Berkeley a través de letras distintivas. He mencionado que se trata tan sólo de cinco notas en el cuaderno $B$ y quince en el cuaderno $A^{15}$. En cuanto al primer cuaderno, en $P C 3$ y 92 (esta última no señalada con letra 'G') el irlandés se preguntó si había sucesión de ideas en el «intelecto divino» o «mente Eterna», como también lo llama. Esto indica, por un lado, que dichos comentarios están inscritos en el contexto de la reflexión sobre el tiempo, pero por otro lado, y cosa aún más importante, que el joven filósofo estaba aún dubitativo sobre cómo hacer compatibles sus postulados con los atributos de la divinidad. Una vez que haya afianzado sus preceptos la respuesta a esta disyuntiva será clara: en Dios no hay sucesión de ideas porque "en Él no hay ningún cambio, variación o sucesión» (Berkeley, 1989, 249).

La siguiente nota a la que quiero referirme -recientemente mencionada- dice así: «G Lo que nos afecta debe ser una cosa pensante pues lo que no piensa no puede subsistir» (PC 109). Esta nota se relaciona con otras dos del cuaderno A, la 780 y la 838. En cuanto a la primera, Berkeley arguye en ella que «S.G. Nihil dat quod non habet o el efecto está contenido en la Causa es un axioma que no Entiendo o creo que sea verdadero». En la segunda nota, la 838, señala lo siguiente: «G. Cada sensación mía que sucede como Consecuencia de las Leyes generales y conocidas de la naturaleza y que viene de fuera es decir independiente de mi Voluntad demuestra el Ser de un Dios. es decir de un Espíritu incorpóreo e inextenso que es omnisciente, omnipotente, etc.». Más allá de que a las notas las relacione su clasificación (haber sido señaladas con la letra ' $G$ '), lo que en realidad las une es que todas vinculan a Dios directamente con el inmaterialismo

14 Advierto que para darle mayor coherencia a los comentarios será necesario en ocasiones reforzarlos con otros, aunque no estén señalados con ' $G$ ' (siempre y cuando versen sobre el tema en cuestión). Lo mismo ocurrirá en el siguiente apartado, es decir, al referirme a las notas no señaladas con ' $G$ ' habrá ocasiones en que me sirva de otras que sí lo estén.

15 En el cuaderno B la letra 'G' (Dios) aparece en 3, 109, 177, 177a, 348. Por su parte, en el cuaderno A aparece en $640,641,675,780,782,805,812,813,825,827,830,831$, $838,845,875$. 
berkeleyano, pues apuntan a que Él, y no la materia (que no puede dar lo que no tiene), es la cosa pensante que nos afecta al producir sensaciones en nosotros que no dependen de la propia voluntad, entre otras cosas porque Dios «no es un agente Ciego», como señala Berkeley en PC 812.

Por otra parte, a lo que estas notas apuntan -aunque aún en ciernes- es al llamado argumento de la pasividad, que Berkeley mencionó en los Principios, sobre todo en la sección sexta, pero desarrolló en los Diálogos, y que se refiere básicamente a que algo activo "nos afecta» al causarnos algún tipo de sensación; eso que nos afecta es además pensante y gracias a su pensar subsiste, es decir, permanece ${ }^{16}$. A pesar de que el irlandés aún no caracterizaba del todo a Dios, como lo hizo tiempo después y en obras posteriores, queda claro que ya pensaba en Él y que lo hacía -y esto es lo más importante- desde la perspectiva de su principio inmaterial.

Otras entradas que quiero destacar pueden abordarse conjuntamente: 177, 177a y 348 respectivamente. En ellas Berkeley inquiere cómo puede ser compleja o compuesta la idea de Dios si su esencia es simple, y al citar a Locke (Luce sitúa esta referencia en II. xxiii 33-35 ["La idea de Dios"] del Ensayo de Locke) se corrobora, una vez más, que el Ensayo fue uno de sus principales referentes al momento de escribir los Comentarios. En las notas 177a y 348, tomadas en ese orden, el filósofo irlandés retomó el tema anterior pero ahora a partir de los postulados del suizo Jean Le Clerc (a quien escribió un par de cartas en 1711). Como respuesta inmediata a su anterior inquisición responde que «omnes reales rerum proprietates continentur in Deo», lo que le hará cuestionar la simplicidad divina mediante la pregunta, formulada en ambas notas, de qué quiere decir que todas las cosas reales sean propiedades contenidas en Dios. Más adelante, en la nota 812 responderá a esta cuestión arguyendo de manera afirmativa que "G.S. Las propiedades de todas las cosas están en Dios esto es hay en la Deidad Entendimiento así como Voluntad». El interés por los atributos divinos vuelve a mostrarse más adelante en otra nota del cuaderno A, en la que no sólo inquiere sino incluso muestra signos de confianza y cierta autoafirmación, al decir que «G.

16 Otra manera de expresar el argumento de la pasividad sería la siguiente: ya que ningún cuerpo que compone el mundo subsiste sin una mente perceptora, entonces mientras no es percibido por mí, es decir por mi mente, o por la de algún otro espíritu creado, o bien no existe en absoluto o existe en la mente de algún «espíritu eterno». Ese espíritu o Dios es el que garantiza la existencia del mundo porque con su percepción lo mantiene o soporta. Principles, II, $\$ 6,43$. En su conocido libro J. Bennett hace una esquematización interesante de este argumento (1988, 217 ss). 
Mi definición de la Palabra Dios creo es Mucho más clara que la de Descartes y Spinoza a saber ens summe perfectum, $\&$ absolute Infinitum or ens constans infinitis attributis quorum unumquodque est infinitum» ( $P C 845)$.

Las entradas anteriores, en su mayoría clasificadas con la letra 'G', demuestran que para 1707-08 Berkeley todavía se encontraba en el proceso de retomar otras opiniones, por lo que según avanzaba en sus lecturas se interrogaba por la veracidad, falsedad o incluso compatibilidad de éstas con su proyecto filosófico, que a pesar de estar muy avanzado aún no estaba totalmente definido.

\subsection{Notas referentes a Dios (no señaladas con ' $G$ ')}

En este apartado no pretendo mencionar cada una de las referencias a Dios que Berkeley no decidió señalar en sus cuadernos con la letra ' $G$ ' ${ }^{17}$, lo que sería fatigoso y poco enriquecedor. Tan sólo quiero aludir a las notas que refieren a los dilemas vistos en Él (respecto a sus atributos, características o a su función dentro del inmaterialismo), así como a las que plantean soluciones a los mismos; pues para entonces Berkeley ya era consciente de la importancia de que Dios encajara perfectamente en su filosofía.

Comenzaré con el cuaderno B para seguir, hasta donde sea posible, el orden de mismos. Allí, específicamente en PC 15, Berkeley barruntó que ciertas características del conocimiento humano se debían a, y estaban relacionadas con, la magnificencia de Dios. «+ La rapidez de las ideas comparada con la del movimiento muestra de la sabiduría de Dios» (vid. Berkeley, 1948-57, II, $\$ 14,46-47$ ).

Por otro lado, en cuanto a las 'potencias' (powers) de que habló Locke en su Ensayo, que Berkeley admitió en algunas partes de sus Comentarios (PC 41, 52 y 80 ), éstas demostraban varias cosas, a saber, 1) «un ser activo y poderoso distinto de nosotros del que dependemos» y 2) que los cuerpos, «entendiendo por ellos combinaciones de potencias", "existen aun cuando no se les perciba, porque son potencias en el Ser activo». Las potencias de Locke eran para Berkeley, en el momento de redactar sus notas, un argumento demostrativo no sólo de ciertos

17 Las notas sobre Dios no señaladas con ' $G$ ' son en torno a trece en el cuaderno B $(P C$ $15,41,52,60,80,83,92,107,144,221,287,290,298)$, y a diecinueve en el A (PC 402, 410, 433, 477a, 485, 499, 499a, 508, 610, 625, 705, 712, 713, 734, 790, 794, 818, 823, $884)$. 
atributos de Dios sino también de la validez axiomática del esse est percipi, pues se sirvió de ellas para mostrar que los cuerpos no dejaban de existir porque no fueran percibidos, dando lugar con esto al papel fundamental de la divinidad como soporte de la existencia (lo que años después le llevó a desarrollar el argumento de la continuidad [en los Principios y sobre todo en los Diálogos] y el que he llamado argumento del sostenedor) ${ }^{18}$.

Las notas 144, 221 y 734 versan sobre las leyes de la naturaleza y su relación, directa o indirecta, con Dios. En cuanto a la naturaleza como tal, incluidas sus leyes, ésta es definida en 734 como «el efecto de la voluntad de Dios y no sabemos cuán pronto puede cambiar». Esta nota se refuerza - por cierto- con otra señalada con letra ' $G$ ', el 794, en donde se dice que la naturaleza no es «algo distinto de la Ordenación de la libre Voluntad de Dios». Estas notas evidencian que para Berkeley la naturaleza dependía de Dios, y por ende Él era el creador de las leyes naturales; sin embargo, también se colige de estos comentarios, a partir de que el filósofo asumiera que no sabemos cuándo cambiarán dichas leyes, que el conocimiento que los hombres pueden tener sobre ellas «no es perfecto y adecuado» (PC 221). Por otro lado, además de que ya se anuncia en las notas el lugar que ocupa Dios en el mundo, como creador y sostén de la naturaleza, también se ve en ellas la limitada condición del conocimiento humano respecto a lo divino, de ahí que no sepamos cuándo cambiará la voluntad de Dios. En el comentario 640 (clasificado igualmente con ' $G$ ') aparece con mayor claridad la relación entre lo humano y lo divino, cuando se dice que así como imaginamos una gran distancia entre el conocimiento del hombre y el de un gusano, «la misma distancia $\dagger$ puede imaginarse entre el Hombre y Dios o Infinitamente mayor».

Los comentarios 287, 290 y 298 son importantes porque en ellos se aborda, al igual que en la alocución berkeleyana Of Infinites de 1707, el "peligro» de hacer que la extensión no dependa de la mente percipiente o, peor aún, que esté en Dios, algo riesgoso que -según la lectura de Berkeley- habían hecho algunos pensadores: «M Parece que Locke, More, Raphson etc hacen extenso a Dios» (PC 298).

M El gran peligro de hacer que la extensión exista sin la mente. en que si se hace debe reconocerse aquélla como infinita inmutable eterna etc. lo

18 Sobre el argumento de la continuidad véase Bennett, 1965, 207-221; PHK, II, \$\$ 45-46, 59-60 y Dialogues, II, 230. Sobre el argumento del sostenedor Dialogues, II, 231 ss. 
que será hacer a Dios extenso (lo que pienso que es peligroso) o bien un ser eterno, inmutable, infinito, increado además de Dios. (PC 290).

La extensión en Dios representaba un serio problema para la religión cristiana, por eso Berkeley reaccionó contra esa concepción arguyendo lo siguiente: «sin embargo, le es muy útil a la religión quitar la extensión de nuestra idea de Dios y poner una potencia en su lugar» (PC 298).

Para terminar con el cuaderno $\mathrm{B}^{19}$, me parece que la nota 107 podría reordenarse y quedar al final del mismo, pues en ella se muestra a un Berkeley más cercano al discurso común, menos filosófico, al hablar de la relación entre el individuo y Dios. En dicha nota el joven filósofo al pensar en los individuos faltos de fe, y por ello carentes de Dios, los pensó como seres impotentes. «+ Extraña impotencia de los hombres. El hombre sin Dios. Más infeliz que una piedra o un árbol, teniendo él sólo el poder de ser miserable por sus voliciones no realizadas, éstas no tienen poder alguno».

En cuanto al cuaderno A, en las notas 410, 433, 477a y 485 respectivamente, se habla de la utilidad del nuevo "Principio» en relación al conocimiento humano y a Dios: «+ Dios sabe hasta qué punto nuestro conocimiento de seres Intelectuales puede ser ampliado a partir del Principio» (PC 410). He dicho antes que para el irlandés Dios funge como causa de todas las cosas naturales (PC 433), incluidos los cuerpos; por eso es que concede que éstos «existen de manera independiente de Nuestra mente» (PC 477a), lo que no significa-como puede colegirse- que dependan de causas ajenas a Dios. El no depender de otras causas, como podría ser la material, es lo que lo llevó a sostener que era superfluo interrogar por causas segundas, por eso afirmó convencido, respecto a Dios y a su principio, que «+ No hay coparticipación entre Dios y la Naturaleza o las Causas segundas en mi Doctrina» (PC 485).

En 499 se ve con mayor claridad que antes el argumento de la pasividad, pues se afirma allí que «Aquellas cosas que suceden desde el exterior no somos la Causa por lo tanto hay alguna otra Causa de ellas es decir hay un ser que dispone estas perfecciones en nosotros». En 499a se añade a la nota anterior que «no ha de decirse nada sino una Voluntad, un ser cuya voluntad resulta ininteligible». Berkeley coligió de aquello que nos afecta y que no es originado por nosotros

19 A pesar de que el cuaderno contiene muchas notas matemáticas y de filosofía natural, puede verse en él la importancia de Dios, aunque aún no como tema central. 
un ser perfecto, el cual era causa de todas las perfecciones sensibles; empero, si este ser perfecto «induce estas perfecciones en nosotros» (PC 499) será porque cuenta con, y actúa acorde a, una "Voluntad», al igual que los «Espíritus Bienaventurados» (PC 610). La relación que se establece entre Dios y los espíritus bienaventurados (o Dios y los hombres) a partir de que cuentan con voluntad, establece ya una semejanza ontológica entre ambos, cuestión que será explicada con mayor amplitud en obras posteriores ${ }^{20}$.

En las notas 625 y 818 Berkeley reconoció el problema de la materia y sus repercusiones en caso de aceptarla, sobre todo respecto a Dios y a la religión cristiana. Es por ello que afirmó en 625 lo siguiente: «M.+ Una vez admitida la materia. Desafío a cualquier hombre a que pruebe que Dios no es materia». Esta actitud crítica lo llevó a reprender a Descartes y a Malebranche por sostener, entre otras cosas, que:

Dios nos ha dado fuertes inclinaciones a pensar que nuestras Ideas proceden de Cuerpos. o que los Cuerpos existen. Ruego me digan qué quieren decir con esto. Consentirían que las Ideas de la imaginación son imágenes de las Ideas del Sentido y vienen de ellas. esto es verdad pero no puede ser lo que quieren decir pues ellos hablan de las Ideas del sentido mismas como si procediesen de o fuesen parecidas a no sé qué. (PC 818).

El propio irlandés respondió a las especulaciones de los materialistas al decir que «M Las Ideas del Sentido son las cosas Reales o Arquetipos. Las Ideas de la Imaginación, los Sueños etc son copias, imágenes de éstas» (PC 823). Como se sabe, la materia fue un asunto central en la filosofía inmaterialista berkeleyana, es por eso que el nombre mismo de 'hipótesis' y luego 'doctrina inmaterial' indicaban claramente su objetivo, a saber, combatir el materialismo y las consecuencias -para Berkeley claramente negativas- que se desprendían de éste.

En las notas 712 y 713, respectivamente, Berkeley aludió a lo que sería su futura ontología de ideas y espíritus. En la primera nota señaló: «S El Espíritu la cosa Activa aquello que es Alma y Dios es sólo la Voluntad Las Ideas son efectos cosas impotentes»; por otro lado, en 713 tuvo cuidado de lo siguiente: «S La

20 La relación de semejanza entre Dios y el hombre aparece en los Principios y en los Diálogos, pero es sobre todo en Alcifrón y en los Sermones donde se habla de ella con mayor detalle. En relación a esto recomiendo la lectura del artículo de José A. Robles sobre la génesis de la noción de sustancia espiritual (1984, 67 ss). 
unión de la Voluntad y el entendimiento debo llamarla Mente no persona, para no ofender, no hay sino una voluntad reconocida que es Dios». Mientras en la primera nota distinguió entre lo activo y lo pasivo, entre el espíritu y la idea, en la segunda estableció la voluntad y el entendimiento como aspectos del ser activo, esto es, del espíritu o mente, a la vez que tuvo cuidado de no perjudicar los dogmas de fe tan preciados por él.

Más adelante, con el comentario 782: «G Absurdo Argumentar la Existencia de Dios a partir de su Idea. no tenemos Idea de Dios. ¡es imposible!», se desprende el importante tema del 'conocimiento nocional', desarrollado años después en los PHK, los Diálogos y en Alcifrón. Mediante este conocimiento Berkeley quiso solucionar el problema de cómo se conocen los espíritus, incluido Dios; para ello argumentó que mientras era imposible tener idea alguna de los seres espirituales sí se podía tener 'noción' de ellos, pues no eran cosas pasivas e inertes, como las ideas o cosas, sino seres activos.

Por otra parte, en el comentario 790 se hace referencia al libro cuarto del Ensayo de Locke (IV, xi 5) y a la sexta meditación de Descartes, porque «usan el mismo argumento para la Existencia de objetos a saber que en ocasiones vemos sentimos etc. contra nuestra voluntad». El retomar en este comentario a Descartes, a quien constantemente descalifica el irlandés en sus cuadernos, se debe seguramente a que estaba pensando en argumentos que sirvieran para su filosofía y a la vez fueran útiles para demostrar la existencia de Dios; en este sentido la referencia a estos dos filósofos anticipa su proyecto de configurar un argumento de tipo 'causal' para la existencia de Dios (como lo fue el argumento de la causalidad), algo que desarrolló años después en los PHK (Berkeley, 194857, II, $\$ 29,53)$.

Por último, las notas 884 y 705 , pese a no estar en orden, dan una buena idea de lo que Berkeley pretendió con su filosofía y específicamente con el tema de Dios. En la primera rechazó "que las cosas se den por necesidad», es decir, que hubiese una causalidad necesaria resultado, por ejemplo, de 'corpúsculos': «todo es el resultado de la libertad es decir todo es Voluntario». Si las mismas leyes de la naturaleza dependían de la voluntad divina, entonces era más apropiado hablar de volición (divina) y no de una mecánica necesidad causal. En la nota 705, acaso la más importante en cuestiones teológico-religiosas, sostuvo que "Dios Debe ser reverenciado. Esto se demuestra Fácilmente una vez que precisamos el significado de la palabra Dios, reverencia, deber». Seguramente el irlandés siguió para esta nota a Locke, quien en su Ensayo (I, iv 7) analizó el principio de adoración y 
mostró que no era innato; sin embargo, lo interesante de la nota es que Berkeley pide una reverencia a la divinidad desde su condición de filósofo, pues mientras pedía fe en Dios desarrollaba toda una filosofía racional para que con ella, y de modo seguro, el hombre propendiese a Él.

\section{Conclusiones}

Para elaborar este artículo decidí retomar una obra poco estudiada, los Comentarios Filosóficos, e investigar en ella un tema fundamental pero, paradójicamente, poco examinado como es el de Dios (basta con ver la casi inexistente bibliografía al respecto). Emprendí esta labor porque si uno conoce la filosofía de Berkeley sabe que Dios juega un papel determinante en ella, y por lo mismo es importante y necesario conocer cómo se fue gestando su concepción de Dios y cuáles fueron los antecedentes de ésta, algo que se encuentra precisamente en los Comentarios.

El objetivo de este artículo fue rastrear, en las notas de los cuadernos, tanto el lugar que ocupaba Dios en los pensamientos del joven filósofo, como la noción que sobre Él tenía en los años 1707-08 (años de redacción de los cuadernos). A pesar de que aún no definía su concepción de Dios, pues todavía se encontraba con ciertas dudas, en los $P C$ ya se percibe una concepción muy cercana a la definitiva, que plasmó en su obra publicada (sobre todo en los Principios, los Diálogos y Alcifrón); esta concepción prefigura a Dios como un ser activo e inextenso, con voluntad y pensamiento, "cosa pensante", pero aún sin entendimiento (por ser un aspecto pasivo que resultaba contradictorio con su actividad). Todavía no se le concibe plenamente como espíritu infinito, pero ya como un ser poderoso que crea y sostiene las leyes de la naturaleza, que resulta inconcebible mediantes ideas pero sí mediante nociones, que no necesita de la materia y que se impone (activamente) al perceptor pasivo. Como se puede ver, muchos de los atributos divinos ya se mencionan en estos cuadernos, aunque no son desarrollados en ellos por tratarse todavía más de barruntos que de certezas.

Por otro lado, en el artículo se pudo ver que en los cuadernos hay unas cincuenta y dos notas que retoman el tema de Dios, treinta y dos más de las señaladas con la letra 'G' (de God, Dios), es decir, según la propia clasificación de los cuadernos. Con esto no quiero decir que los $P C$ sean un libro apologético de la divinidad, ni tampoco que ahonden ampliamente en el tema, como no lo hacen con ningún otro; lo que sí quise mostrar es que en los cuadernos está 
presente el interés por Dios, incluso en mayor medida de lo que señala la propia clasificación, y no como una cuestión complementaria sino más bien como una central para la naciente filosofía del irlandés.

Para concluir quiero parafrasear a John Wild, quien en su clásico libro sobre Berkeley sostuvo acertadamente que el verdadero significado del «nuevo principio» inmaterialista, ya formulado en los $P C$, es que el mundo, el yo y Dios, es decir, todas la cosas, no son fragmentos desunidos ni entidades separadas sino que están íntimamente entrelazados en un todo, sin lo cual cualquiera de ellos sería impensable $(1962,25)$. Lo dicho por Wild confirma la importancia de Dios en la filosofía de Berkeley, lo que corrobora que todo aquél que quiera tener un buen conocimiento de su pensamiento debe comenzar por entender cómo se fue conformando su noción de Dios; para ello resulta imprescindible estudiar las notas que conforman los Comentarios, tal y como se hizo en este artículo.

\section{Bibliografía}

BELFRAGE, Bertil (1985). "The Order and Dating of Berkeley's Notebooks". Revue Internationale de Philosophie 154, pp. 196-214.

— (1985). "The Clash on semantics in Berkeley's 'Notebook A"'. Hermathena 39, Winter, pp. 117-126.

BENNETT, Jonathan (1988). Locke, Berkeley, Hume: Temas Centrales. (Tr. Robles, J. A.). México: IIF's-UNAM.

- (1965). "Berkeley and God". Philosophy 40, pp 207-221.

BERKELEY, George (1989). Comentarios Filosóficos. Introducción manuscrita a los Principios del conocimiento humano. Correspondencia con Johnson. (Tr. Robles, J. A.). México: IIF's-UNAM.

- (1985). CEuvres I. (Ed. Brykman, G.), Paris: Presses Universitaires de France.

- (1948-57). The Works of George Berkeley, Bishop of Cloyne, 9 vols. Eds. A. A. Luce y T. E. Jessop, Edinburgh: Nelson \& Sons Ltd.

FURLONG, E. J. (1961-63). “Two Notes on Berkeley's 'Philosophical Commentaries"'. Proceedings of the Royal Irish Academy, Section C 62, pp. 1-8.

JOHNSTON, G. A. (1930). Berkeley's Commonplace Book. London: Faber \& Faber. 
LOCKE, John (2005). Ensayo sobre el entendimiento humano. México: FCE.

LORENZ, Theodor (1905). "Weitere Beiträge zur Lebensgeschichte George Berkeleys". Archiv für Geschichte der Philosophie 18, no. 4, Januar, pp. 551-556.

LUCE, A. A. (1942-43). "The purpose and the Date of Berkeley's Commonplace Book. With an Appendix of Berkeley's Birthplace". Proceedings of the Royal Irish Academy, Section C 48, pp. 273-289.

- (1970). "Another look at Berkeley's Notebooks". Hermathena 110, pp. 5-23.

ROBLES, J. A. (1990). Estudios berkeleyanos. México: IIF's-UNAM.

- (1984). "Génesis de la noción de sustancia espiritual en la filosofía de George Berkeley I”. Diánoia, vol. 30, no. 30, pp. 67-87.

SZAŁEK, Piotr, K. (2009). "On the Origins of the Berkeleian Definition of 'Existence". Studies in Logic, Grammar and Rethoric 15, 28, pp. 145-159.

WILD, John (1962). George Berkeley: A Study of His Life and Philosophy. New York: Russell and Russell Inc.

Enviado: 27/01/2015

Aceptado: 4/07/2015

Este trabajo se encuentra bajo una licencia de Creative Commons Reconocimiento-

NoComercial-SinObraDerivada 4.0

\section{(c) $(1) \Theta \Theta$}


